OPEN ACCESS

Edited by: Yasuyuki Saito,

Kobe University, Japan

Reviewed by:

Shigeyoshi Fujiwara,

National Center for Child Health

and Development (NCCHD), Japan

Baochun Zhang,

Dana-Farber Cancer Institute,

United States

*Correspondence:

Christian Münz

christian.muenz@uzh.ch

Specialty section:

This article was submitted to Cancer Immunity and Immunotherapy,

a section of the journal

Frontiers in Immunology

Received: 08 July 2020

Accepted: 17 August 2020

Published: 09 September 2020

Citation:

Münz C (2020) Probing Reconstituted Human Immune Systems in Mice With Oncogenic

$\gamma$-Herpesvirus Infections.

Front. Immunol. 11:581419. doi: 10.3389/fimmu.2020.581419

\section{Probing Reconstituted Human Immune Systems in Mice With Oncogenic $\gamma$-Herpesvirus Infections}

\author{
Christian Münz* \\ Viral Immunobiology, Institute of Experimental Immunology, Zurich, Switzerland
}

Mice with reconstituted human immune systems can mount cell-mediated immune responses against the human tumor viruses Epstein Barr virus (EBV) and Kaposi sarcoma associated herpesvirus (KSHV). Primarily cytotoxic lymphocytes protect the vast majority of persistently infected carriers of these tumor viruses from the respective malignancies for life. Thus, EBV and KSHV infection can teach us how this potent immune control is induced, what phenotype and functions characterize the protective lymphocyte compartments and if similar immune responses could be induced by vaccination. This review will summarize similarities and differences between EBV and KSHV associated pathologies and their immune control in patients and mice with reconstituted human immune systems. Furthermore, it will high-light which aspects of the near perfect immune control can be modeled in the latter preclinical animal models and discuss their relevance for cancer immunology in general.

Keywords: Epstein Barr virus, Kaposi sarcoma associated herpesvirus, primary effusions lymphoma, diffuse large B cell lymphoma, T cells, NK cells, NKT cells

\section{INTRODUCTION ON EBV AND KSHV SPECIFIC IMMUNE CONTROL}

The two human $\gamma$-herpesviruses Epstein Barr virus (EBV) and Kaposi sarcoma associated herpesvirus (KSHV) are WHO class I carcinogens (1-3). They are associated with lymphomas, Hodgkin's and Burkitt's in the case of EBV, and primary effusion lymphoma (PEL), and multicentric Castleman's disease (MCD) for KSHV (4). Furthermore, EBV causes epithelial cell tumors, like nasopharyngeal and $10 \%$ of gastric carcinoma (5), while KSHV is the etiological cause of the endothelial cell derived cancer Kaposi sarcoma (3). Fortunately, these malignancies are rare with incidence rates of less than 1 in $10^{4}$ individuals, even so more than $95 \%$ of the human adult population is persistently infected with EBV, and more than $50 \%$ of the Sub-Saharan African population with $\operatorname{KSHV}(3,6)$. However, EBV and KSHV associated lymphomas as well as Kaposi sarcoma develop at increased frequencies after immune suppression, due to for example human immunodeficiency virus (HIV) infection or iatrogenic treatment after transplantation $(7,8)$. Moreover, primary immunodeficiencies, often caused by individual gene mutations, can predispose for EBV and KSHV associated diseases (9). Interestingly, the affected genes point toward well defined immune compartments that control EBV and KSHV infection and prevent associated malignancies in most virus carriers. Even so EBV and KSHV are closely related $\gamma$-herpesviruses, the requirements for their immune control seem to be quite dissimilar. Primary immunodeficiencies that predispose for EBV associated diseases affect the cytotoxic machinery of lymphocytes, 
including natural killer (NK) and $\mathrm{CD}^{+} \mathrm{T}$ cells $(10,11)$. In addition, co-stimulatory molecules on these cytotoxic lymphocytes, like CD27, 4-1BB, 2B4, and NKG2D, seem to be required to control EBV. A third group of molecules that are required for EBV specific immune control, are involved in $\mathrm{T}$ cell receptor signaling, such as interleukin-2 inducible $\mathrm{T}$ cell kinase (ITK), ZAP70, and PI3K. Finally, gene products that support and sustain cytotoxic lymphocyte development and expansions, like MCM4, CTPS1, and XIAP, are required for EBV specific immune control. Surprisingly, type I and II interferons (IFNs) as well as antibody responses are dispensable for the immune control of EBV (11). In contrast, type II IFN signaling with IFN- $\gamma$ receptor 1 and STAT4 protects from Kaposi sarcoma $(9,12)$. In addition, OX40 instead of the above mentioned co-stimulatory molecules is required to protect from Kaposi sarcoma (13). Thus, primary immunodeficiencies suggest that cytotoxic lymphocytes keep persistent EBV infection in check, while their cytokine production protects in addition from KSHV. Accordingly, these two pathogens are suitable to challenge human immune systems with their tumorigenic potential and test their robustness in raising cell-mediated immune responses.

\section{VIRUS ASSOCIATED MALIGNANCIES}

Such challenges are for example applied to immune compromised mice with reconstituted human immune system components, such as NOD-scid $\gamma_{c}^{-/-}$that are neonatally injected with human $\mathrm{CD}^{+} 4^{+}$hematopoietic progenitor cells (HPCs) and then develop human leucocytes during three to 6 months (humanized mice) $(14,15)$ (Figure 1). In order, however, to explore the protective capacity of the reconstituted human immune system compartments, at least some of the EBV and KSHV associated pathologies must be recapitulated in these humanized mouse systems. Accordingly, the viral gene expression patterns have been analyzed after EBV infection of humanized mice (16-21). In most of these studies a high dose of infectious viral particles from the B95-8 EBV strain, originally isolated during symptomatic primary infection called infectious mononucleosis (IM), was used. As in secondary lymphoid tissues, including tonsils, of IM patients (22) primarily EBV infected $\mathrm{B}$ cells expressing the latency III infection program with six nuclear antigen (EBNA1, 2, 3A-C, and LP), two latent membrane proteins (LMP1,2) as well as non-translated EBER and viral miRNAs, were observed (21). In addition, however, low levels of latency I and II with EBNA1 as the sole or in addition LMP1 and 2 protein expression could be detected (18, 23). Low levels of these lower latencies were also verified by detection of characteristic viral transcripts $(21,24,25)$. While latency III is found in naïve B cells of healthy EBV carriers, latency II predominates in germinal center B cells and latency I in homeostatically replicating memory $B$ cells $(26,27)$. It is unclear if the respective latencies are also in similar B cell differentiation stages in humanized mice. In humans, EBV persists without viral protein expression in circulating memory $\mathrm{B}$ cells of so-called latency 0 (28). This latency 0 can also be reached in humanized mice (20). From latency 0 and I EBV switches into lytic replication upon plasma cell differentiation in healthy virus carriers (29). Such reactivation only rarely occurs with the B95-8 EBV virus in humanized mice (30), but other viruses such as the M81 EBV strain are more prone to lytic replication $(31,32)$. In contrast to these IM-like infections, lower viral doses might mimic asymptomatic primary infection, as it occurs in the vast majority of humans (6), but these have so far not extensively been explored in humanized mice (33). Nevertheless, all EBV infection programs can be found upon usually intraperitoneal inoculation of humanized mice.

According to the predominance of EBV latency III infection the virus-associated lymphomas that develop in up to one third of infected mice also carry this strongly growth transforming gene expression program akin to some diffuse large B cell lymphomas (DLBCL) and in vitro EBV transformed, B cell derived lymphoblastoid cell lines (LCLs) (2). Burkitt's and Hodgkin's lymphomas that carry latency I and II have so far not been reported. DLBCL-like lymphomagenesis can further be increased by infection with an EBV strain that is deficient in the viral tumor suppressor EBNA3B (34). Accordingly, EBNA3B loss has also be found in a subset of DLBCLs in human patients $(34,35)$. Furthermore, both EBV and KSHV are present in most PELs (36). Of all KSHV associated malignancies PEL cells are also the only one that maintains KSHV in culture (37). Interestingly, KSHV infection only persists in humanized mice upon co-infection with $\operatorname{EBV}(23,38)$. Similarly, both viruses or their monkey orthologues seem to be co-transmitted in both macaques and humans $(39,40)$. Furthermore, EBV supports $\mathrm{KSHV}$ infection of B cells in vitro (41). KSHV and EBV coinfection of humanized mice also allows for the development of PEL-like lymphomas (Figure 1) with characteristics of plasma cell differentiation that have previously been defined for PELs $(23,42)$. Consistent with lytic EBV replication being associated with plasma cell differentiation (29) both PEL-like tumors in humanized mice and human PELs displayed elevated lytic viral gene products and this lytic EBV replication contributed to enhanced tumor formation in double-infected humanized mice (23). Thus, EBV associated DLBCLs and KSHV as well as EBV positive PELs can be elicited in humanized mice.

\section{IMMUNE CONTROL BY INNATE LEUKOCYTES}

The symptomatic primary EBV infection IM is an immunopathology caused by massive expansion of $\mathrm{CD}^{+}$ $\mathrm{T}$ cells that are predominantly directed against lytic EBV antigens (43). This disease is rare in children but can make up 30 to $50 \%$ of primary infections in adolescents (6). Therefore, EBV infection at young age seems to trigger a different immune response than later in life. One reason for this altered immune response could be more robust innate immune control of lytic EBV infection in children. Along these lines it has been shown that NK cells protect from lytic EBV infection in humanized mice $(19,44)$ (Figure 1). In both humanized mice and pediatric IM patients primarily early differentiated CD56 ${ }^{\mathrm{dim}} \mathrm{NKG} 2 \mathrm{~A}^{+}$killer immunolglobulinlike receptor (KIR) ${ }^{-}$NK cells expand $(19,45-48)$. While these 


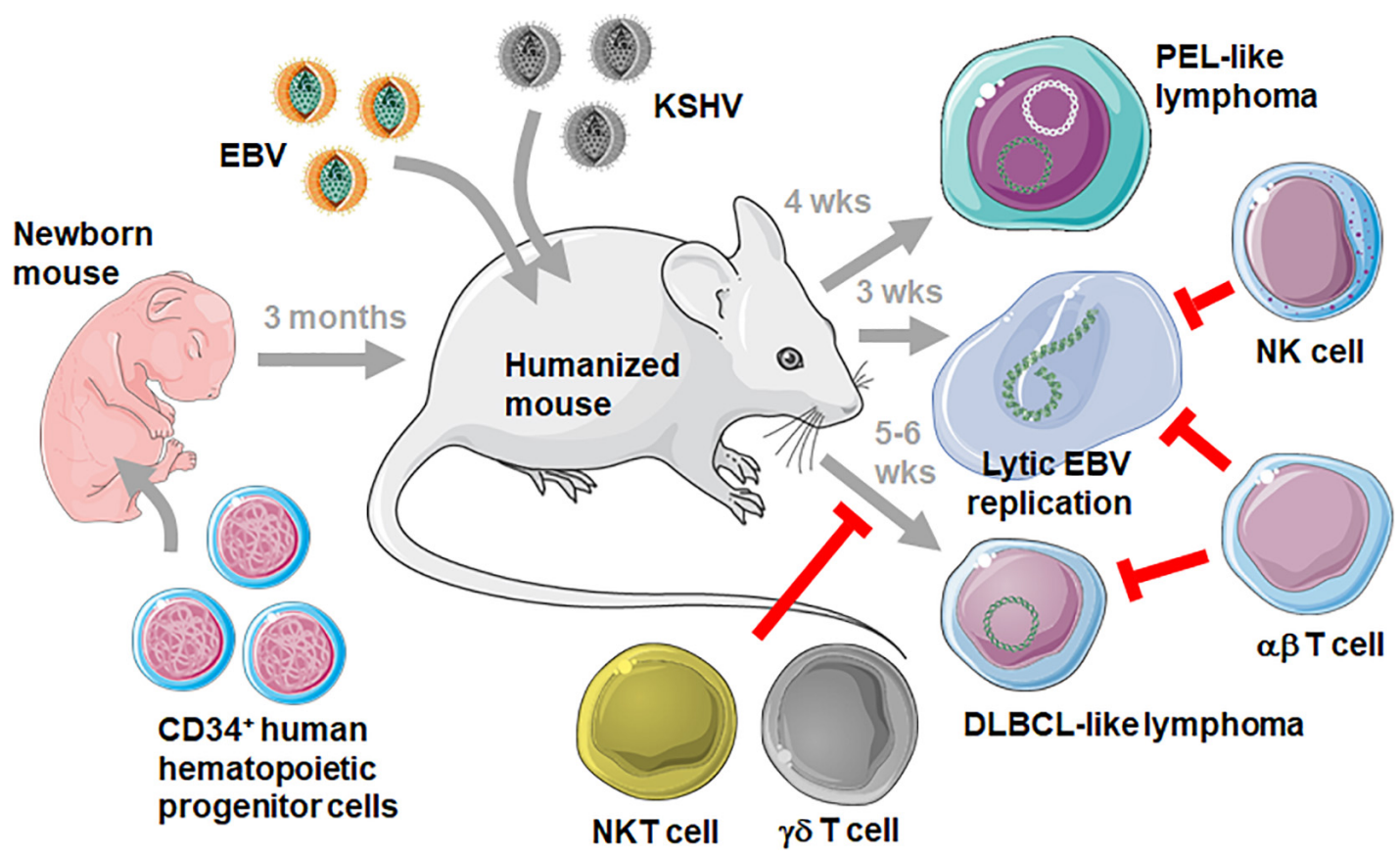

FIGURE 1 | Challenging humanized mice with EBV and KSHV infection. Mice with reconstituted human immune system compartments (humanized mice) are generated by injecting human CD34+ HPCs into immune compromised mice, such as the NOD-scid $\gamma_{c}{ }^{-/-}$mouse strain. After 3 months humanized mice can be infected with EBV with and without KSHV. Persistent infection with these two viruses develops into PEL-like lymphomas after double infection after 4 weeks (wks), EBV Iytic replication can be observed after 3 weeks and DLBCL-like lymphomas develop after 5-6 weeks. While the immune control of KSHV in humanized mice still needs to be defined, NK and $\alpha \beta$ T cells control lytic EBV replication, and NKT, $\gamma \delta$ T and $\alpha \beta$ T cells prevent DLBCL-like tumorigenesis by targeting latent EBV infection. This figure was created in part with modified Servier Medical Art templates, which are licensed under a Creative Commons Attribution 3.0 unported license: https://smart.servier.com.

are the most abundant $\mathrm{NK}$ cell subpopulation after birth in humans, they differentiate to $\mathrm{CD} 56^{\mathrm{dim}} \mathrm{NKG} 2 \mathrm{~A}^{-} \mathrm{KIR}^{+} \mathrm{NK}$ cells during the first decade of life (45), possibly rendering adolescents more susceptible to IM. It has been suggested that ligands for the activating NK cell receptors NKG2D and DNAM1 get up-regulated on $\mathrm{B}$ cells that undergo lytic EBV reactivation, and that NKG2D and DNAM1 mediate NK cell cytotoxicity against the respective targets (49). Thus, NK cell differentiation could diminish protective NK cell populations during the first decade of life, compromising innate immune control of lytic EBV infection which in turn would trigger the massive expansion of lytic EBV antigen specific CD8 ${ }^{+} \mathrm{T}$ cells, causing IM.

However, in addition to NK cells other innate lymphocyte populations might play a role during EBV infection. Along these lines it has been shown that $\mathrm{V} \gamma 9 \mathrm{~V} \delta 2 \mathrm{~T}$ cells that recognize mevalonate metabolism intermediates presented by butyrophilin 2A1 (BTN2A1) prevent EBV associated lymphoproliferative disease in humanized mice (50). Similarly, the transfer of V $\gamma 9 \mathrm{~V} \delta 2$ $\mathrm{T}$ cells inhibited tumor growth in EBV transformed B cell carrying mice (51). V $\gamma 9 \mathrm{~V} \delta 2 \mathrm{~T}$ cells recognized EBV infected B cells by their T cell receptor and NKG2D as a co-receptor (50). Especially EBV latency I Burkitt's lymphoma cell lines expanded human V $\gamma 9 \mathrm{~V} \delta 2 \mathrm{~T}$ cells (52). These lymphoma cell lines displayed the highest levels of mevalonate metabolite presentations on BTN2A1. Interestingly, only around $50 \%$ of human individuals could raise these protective $\mathrm{V} \gamma 9 \mathrm{~V} \delta 2 \mathrm{~T}$ cell responses against
EBV infected targets (52). These so-called group 1 individuals harbor a high frequency of $\mathrm{V} \gamma 9 \mathrm{~V} \delta 2 \mathrm{~T}$ cells with $\mathrm{T}$ cell receptors that utilize $J \gamma \mathrm{P}$ segments (53). These $\mathrm{V} \gamma 9 \mathrm{~J} \gamma \mathrm{P}$ T cells expanded upon stimulation with Burkitt's lymphoma cell lines. Thus, V $\gamma 9 \mathrm{~V} \delta 2 \mathrm{~T}$ cells might protect preferentially against EBV latency I infected B cells.

Finally, there might also be a role for NKT cells that recognize glycolipid presentation on CD1d non-classical MHC class I molecules $(54,55)$. Adoptive transfer of NKT cells into mice that carried EBV transformed B cells reduced their tumor formation (54). They seemed to recognize freshly EBV infected B cells and EBV latency II infected tumor cells, while CD1d is downregulated on EBV latency III infected B cells (55). Along these lines, X-linked lymphoproliferative (XLP-1) disease which affects primarily boys due to mutations in the 2B4 adaptor SAP and which confers life-threatening susceptibility to EBV associated pathogenesis, lack NKT cells (56). Thus, NKT cells might also contribute to innate immune control of latently EBV infected B cells, possibly preferentially expressing the latency II program. Humanized mice have contributed to demonstrate immune control by NK, V $\gamma 9 \mathrm{~V} \delta 2 \mathrm{~T}$ cells, and NKT cells against lytic and latent EBV infected B cells, respectively. Only fully transformed EBV latency III B cells, resembling DLBCLs, do not seem to be efficiently recognized by innate lymphocytes, but these seem to target EBV infected precursors that are required for DLBCL-like tumor development in humanized mice (Figure 1). 


\section{CYTOTOXIC T CELL RESPONSES}

In contrast to innate lymphocytes, EBV latency III infected B cells that can be also generated in vitro by EBV infection of human $\mathrm{B}$ cells, are highly immunogenic for $\mathrm{T}$ cells. Indeed, adoptive transfer of LCL stimulated $\mathrm{T}$ cell lines into patients with EBV induced post-transplant lymphoproliferative disease (PTLD) was one of the first cellular therapies and was able to cause PTLD regression (57). The EBV antigens EBNA1, LMP1, and LMP2 have proven to be sufficient as $\mathrm{T}$ cell targets for such adoptive $\mathrm{T}$ cell transfer therapies against $\mathrm{EBV}$ associated malignancies $(58,59)$. Similarly in humanized mice antibody mediated $\mathrm{T}$ cell depletion increased EBV viral loads and DLBCLlike lymphomagenesis $(16,60)$ (Figure 1 ). While primarily $\mathrm{CD}^{+}$ $\mathrm{T}$ cells seemed to protect from EBV induced lymphomagenesis in humanized mice, antibody depletion, pharmacological inhibition by FK506 or destruction of $\mathrm{CD} 4^{+} \mathrm{T}$ cells by HIV co-infection also compromised EBV specific immune control in humanized mice $(16,21,25)$. Along these lines, late lytic EBV antigen specific $\mathrm{CD} 4^{+} \mathrm{T}$ cells have been reported to restrict EBV transformed $\mathrm{B}$ cell growth in mice (61). Thus, both cytotoxic $\mathrm{CD}^{+} \mathrm{T}$ cells and helper $\mathrm{T}$ cell functions seem to be required for adaptive immune control of EBV in humanized mice.

Antibody blocking and recombinant EBV mutant infection experiments have revealed crucial aspects of this $\mathrm{T}$ cell mediated immune control of EBV in humanized mice and helped to explain the mechanistic underpinnings of EBV susceptibility in patients with the above mentioned primary immunodeficiencies. Among the co-stimulatory molecules, blocking of 2B4, one of the receptors that depends on SAP for activating signaling and is affected in XLP-1, led to increased EBV loads and lymphomagenesis (62). This $2 \mathrm{~B} 4$ requirement was mainly on $\mathrm{CD}^{+} \mathrm{T}$ cells because their antibody mediated depletion did not further increase viral titers and tumor formation. In addition, $\mathrm{CD}^{+} \mathrm{T}$ cells with the inhibitory co-receptor PD1 expanded during IM and in EBV infected humanized mice $(33,63)$. They included both latent (LMP2) and lytic (BMLF1) EBV antigen specific $\mathrm{CD}^{+} \mathrm{T}$ cells. These $\mathrm{PD}-1$ positive $\mathrm{CD}^{+} \mathrm{T}$ cells carried the highest cytotoxic ability during EBV infection of humanized mice. Furthermore, they expressed CXCR5, Tim-3, KLRG1, and TCF-1 (33) and resembled germinal center homing $\mathrm{CD}^{+} \mathrm{T}$ cells which have previously been described to contain EBV specific $\mathrm{CD}^{+} \mathrm{T}$ cells in human tonsils (64). Interestingly, antibody blocking of PD-1 led to increased EBV viral loads and lymphomagenesis. This was associated with IL-10 production and might therefore represent activation of a regulatory $\mathrm{CD} 4^{+} \mathrm{T}$ cell population during $\mathrm{PD}-$ 1 inhibition that compromises EBV specific immune control. Along these lines, at least a subset of patients that undergo PD-1 blockade for tumor treatment and develop neurological side effects, have recently been shown to harbor elevated EBV loads and accumulate EBV infected B cells and EBV reactive $\mathrm{CD}^{+}$and $\mathrm{CD}_{8}^{+} \mathrm{T}$ cells in their central nervous system (65). In contrast to PD-1 blockade on regulatory $\mathrm{CD}^{+} \mathrm{T}$ cells, humanized mouse models that sustained only $\mathrm{T}$ and $\mathrm{EBV}$ transformed $\mathrm{B}$ cell reconstitution developed exhausted, presumably $\mathrm{CD} 8^{+} \mathrm{T}$ cell populations and antibody blocking of their PD-1 and CTLA-4 inhibitory receptors restored EBV specific immune control (66). Antibody blocking studies have, therefore, suggested essential roles for PD1, CTLA-4, and 2B4 during EBV specific immune control in humanized mice.

Additional characteristics of protective EBV specific $T$ cell responses have been revealed by recombinant EBV mutant viruses. In addition to secondary lymphoid tissue homing, CXCR3 dependent $\mathrm{T}$ cell homing to inflamed tissues has been found to be critical for immune control of EBV in humanized mice by studying EBNA3B deficiency (34). EBNA3B deficiency which was observed in some patients with DLBCL $(34,35)$, elicited elevated lymphomagenesis in humanized mice (34). The respective tumors were devoid of $\mathrm{T}$ cell infiltrates and EBNA3B deficient LCLs were found to produce less of the CXCR3 stimulating CXCL9 and 10 chemokines. Transgenic CXCL10 expression by EBNA3B deficient LCLs restored their $\mathrm{T}$ cell mediated immune control in vivo. In addition, compromised MHC class I antigen presentation by EBV miRNAs limits EBV specific immune control (67). miRNA deficient EBV did not induce any DBLCL-like lymphomas in humanized mice, but tumor formation was restored upon antibody mediated $\mathrm{CD} 8^{+} \mathrm{T}$ cell depletion. Both latent and at least early lytic $\mathrm{CD}^{+} \mathrm{T}$ cell responses might contribute to $\mathrm{CD}^{+} \mathrm{T}$ cell mediated immune protection against EBV associated lymphomagenesis in humanized mice $(18,30)$. EBV deficient in the immediate early lytic EBV transactivator BZLF1 was compromised in its ability to cause DLBCL-like lymphomas in humanized mice, KSHV co-infection increased lytic EBV replication and lymphomagenesis, and BMLF1 specific $\mathrm{CD}^{+} \mathrm{T}$ cells were able to transiently control lytic EBV infection after their adoptive transfer $(18,23,30)$. These studies define CXCR3 dependent homing, targeting of early lytic EBV antigens and efficient MHC class I antigen presentation as additional characteristics of EBV specific immune control by $\mathrm{T}$ cells.

In contrast to $\mathrm{CD}^{+} \mathrm{T}$ cells, $\mathrm{CD} 4^{+} \mathrm{T}$ cells can, however, also mediate pro-tumorigenic effects. LMP1 deficient EBV required $\mathrm{CD}_{4}^{+} \mathrm{T}$ cells for DLBCL-like lymphoma formation in humanized mice (68). Furthermore, $\mathrm{CD} 4^{+} \mathrm{T}$ cells allowed EBV to access the Burkitt's and Hodgkin's lymphoma associated EBV latencies I and II in humanized mice, even so no tumors with these viral gene expression patterns have so far been observed in any humanized mouse model (24). Therefore, both anti- and pro-tumorigenic functions of $\mathrm{T}$ cells can be studied during EBV infection of humanized mice, and so far, $\mathrm{CXCR}^{+}{ }^{+} \mathrm{CXCR} 5^{+} 2 \mathrm{~B} 4^{+} \mathrm{CD} 8^{+} \mathrm{T}$ cells have emerged as the main protective entity.

\section{VACCINATION}

Epstein Barr virus specific immune control is uniquely dependent on cell mediated immunity and cytotoxic lymphocytes, while individuals with deficient antibody responses do not suffer from EBV associated pathologies (9-11). This cytotoxic immune 
control of EBV can be recapitulated in humanized mice (14). Therefore, humanized mice should be well suited to test EBV specific vaccine candidates and develop vaccines that efficiently prime cytotoxic lymphocytes and are also required to stimulate other anti-tumor immune protection (69). Unfortunately, it has been quite frustrating to identify vaccine candidates that manage to induce such protective $\mathrm{T}$ cell responses. Antigen targeting to dendritic cells (DCs), recombinant viral vectors, and virus like particles (VLP) have been explored.

Even so EBNA1 specific $T$ cells have been therapeutically used against PTLD (58) and this antigen is incorporated in many vaccine formulations (70-74), targeting of EBNA1 to DCs and uptake via their DEC-205 receptor has elicited only weak $\mathrm{CD}^{+} \mathrm{T}$ cell responses $(75,76)$. However, even in regular mice this vaccine formulation was even with a boost by a recombinant adenovirus encoding EBNA1 less efficient in inducing $\mathrm{T}$ cell responses than heterologous prime-boost vaccination with EBNA1 encoding adenovirus and modified vaccinia virus Ankara (MVA) (74). In contrast, an EBV derived VLP into which EBNAl was incorporated as a tegument component elicited protective $\mathrm{CD} 4^{+} \mathrm{T}$ cell responses against EBV challenge in humanized mice (77). This VLP targets $B$ cells as EBV does, and the abundance of these antigen presenting cells (APCs) in humanized mice could facilitate the priming of sufficient numbers of protective $\mathrm{T}$ cells. Similarly, yellow fever virus (YFV) specific vaccination that is based on the attenuated viral strain YFV17D required human DC expansion prior to YFV17D injection to prime significant $\mathrm{T}$ cell responses (78). Such expanded APC populations, as exemplified by the high constitutive $\mathrm{B}$ cell reconstitution in humanized mice and Flt3L mediated DC expansion might overcome the paucity in secondary lymphoid tissue development that most humanized mouse models suffer from (79). Interestingly, adoptive transfer of DC populations did not only increase these APC populations and allowed for more efficient induction of human cytomegalovirus (HCMV) specific immune responses in humanized mice, but also induced the formation of secondary lymphoid tissues like lymph nodes (80). These structures then did not only facilitate the priming of $\mathrm{T}$ cell, but also antibody responses (80). Thus, humanized mice allow for the evaluation of vaccines, but might require expansion of APC populations and secondary lymphoid tissues for them to meet naive $\mathrm{T}$ cells for adaptive cell-mediated and possibly even humoral immune response induction.

\section{CONCLUSION AND OUTLOOK}

Humanized mice hold the promise that human immune responses and their modulation by immunotherapies as well as vaccinations can be studied. However, at least humoral immune responses are severely attenuated in these mice and mucosal immune reconstitution is only rudimentary. As a result, only few pathogens have been shown to elicit protective immune responses in humanized mouse systems. As these models get further improved by introduction of human MHC and cytokine genes, as well as additional human organoids (15) immunocompetence will probably increase. However, already with the available models strongly $\mathrm{T}$ cell immunogenic pathogens like EBV and KSHV can be characterized for their infection, tumorigenesis, and cell-mediated immune control. Indeed, EBV is the pathogen that most often leads to even pathogenic $\mathrm{CD}^{+} \mathrm{T}$ cell expansions in humans, as in IM, and primary immunodeficiencies as well as therapeutic adoptive $\mathrm{T}$ cell transfer suggest that such cytotoxic lymphocyte responses are necessary and sufficient for its immune control $(9,43,81)$. This suggests that EBV is well suited to interrogate the immunocompetence of cytotoxic lymphocyte compartments in humanized mice and should be able to reveal improvements of these preclinical in vivo models.

At the same time any manipulation of $\mathrm{T}$ cell mediated immune control, like immune checkpoint inhibition, can be assessed for its ability to improve or compromise EBV specific immune control, even if the respective treatments are developed for other tumors than EBV associated malignancies. The influence of these treatments on EBV infection should still be of interest because the vast majority of adult humans ( $>95 \%)$ are persistently infected with EBV (2) and, therefore, any immune modulation of antitumor $\mathrm{T}$ cell responses will also affect $\mathrm{EBV}$ specific immune control in the respective patients, as becomes apparent during immunosuppressive treatment after transplantation, increasing the risk for PTLD $(7,21)$. Thus, EBV infected humanized mice constitute an interesting preclinical in vivo system to test human immune modulators.

Finally, it remains difficult to construct humanized mice with tumors and long-term engraftment of diverse autologous human immune system components (15). However, the growth transforming ability of EBV allows for the generation of autologous tumor cells that can be genetically manipulated and afterward implanted into humanized mice that have been reconstituted with $\mathrm{CD} 34^{+}$HPCs from the same donor. Therefore, it is one of the few systems that currently allow studying tumor interaction with human immune system components in an autologously xenografted humanized mouse model. All these advantages should allow us to interrogate human immune responses and design vaccines as well as other immunotherapies to elicit them more comprehensively.

\section{AUTHOR CONTRIBUTIONS}

CM wrote the manuscript.

\section{FUNDING}

Research in CM's laboratory is supported by Cancer Research Switzerland (KFS-4091-02-2017 and KFS-4962-02-2020), KFSPPrecision $^{\mathrm{MS}}$ and HMZ ImmunoTargET of the University of Zurich, Cancer Research Center Zurich, the Sobek Foundation, the Vontobel Foundation, the Baugarten Foundation, the Swiss Vaccine Research Institute, Roche, Novartis, and the Swiss National Science Foundation (310030B_182827 and CRSII5_180323). 


\section{REFERENCES}

1. Bouvard V, Baan R, Straif K, Grosse Y, Secretan B, El Ghissassi F, et al. A review of human carcinogens-Part B: biological agents. Lancet Oncol. (2009) 10:321-2. doi: 10.1016/s1470-2045(09)70096-8

2. Münz C. Latency and lytic replication in the oncogenesis of the Epstein Barr virus. Nat Rev Micobiol. (2019) 17:691-700. doi: 10.1038/s41579-019-0249-7

3. Cesarman E, Damania B, Krown SE, Martin J, Bower M, Whitby D. Kaposi sarcoma. Nat Rev Dis Primers. (2019) 5:9.

4. Cesarman E. Gammaherpesviruses and lymphoproliferative disorders. Annu Rev Pathol. (2014) 9:349-72. doi: 10.1146/annurev-pathol-012513-104656

5. Shannon-Lowe C, Rickinson A. The global landscape of EBV-associated tumors. Front Oncol. (2019) 9:713. doi: 10.3389/fonc.2019.00713

6. Dunmire SK, Verghese PS, Balfour HH Jr. Primary Epstein-Barr virus infection. J Clin Virol. (2018) 102:84-92.

7. Gottschalk S, Rooney CM, Heslop HE. Post-transplant lymphoproliferative disorders. Annu Rev Med. (2005) 56:29-44.

8. Totonchy J, Cesarman E. Does persistent HIV replication explain continued lymphoma incidence in the era of effective antiretroviral therapy? Curr Opin Virol. (2016) 20:71-7. doi: 10.1016/j.coviro.2016.09.001

9. Damania B, Münz C. Immunodeficiencies that predispose to pathologies by human oncogenic gamma-herpesviruses. FEMS Microbiol Rev. (2019) 43:18192. doi: 10.1093/femsre/fuy044

10. Tangye SG, Latour S. Primary immunodeficiencies reveal the molecular requirements for effective host defense against EBV infection. Blood. (2020) 135:644-55. doi: 10.1182/blood.2019000928

11. Latour S, Fischer A. Signaling pathways involved in the T-cell-mediated immunity against Epstein-Barr virus: lessons from genetic diseases. Immunol Rev. (2019) 291:174-89. doi: 10.1111/imr.12791

12. Jackson CC, Dickson MA, Sadjadi M, Gessain A, Abel L, Jouanguy E, et al. Kaposi sarcoma of childhood: inborn or acquired immunodeficiency to oncogenic HHV-8. Pediatr Blood Cancer. (2016) 63:392-7. doi: 10.1002/pbc. 25779

13. Byun M, Ma CS, Akcay A, Pedergnana V, Palendira U, Myoung J, et al. Inherited human OX40 deficiency underlying classic Kaposi sarcoma of childhood. J Exp Med. (2013) 210:1743-59. doi: 10.1084/jem.20130592

14. McHugh D, Caduff N, Murer A, Engelmann C, Deng Y, Zdimerova H, et al. Infection and immune control of human oncogenic gamma-herpesviruses in humanized mice. Philos Trans R Soc Lond B Biol Sci. (2019) 374:20180296. doi: 10.1098/rstb.2018.0296

15. Stripecke R, Münz C, Schuringa JJ, Bissig KD, Soper B, Meeham T, et al. Innovations, challenges, and minimal information for standardization of humanized mice. EMBO Mol Med. (2020) 12:e8662.

16. Strowig T, Gurer C, Ploss A, Liu YF, Arrey F, Sashihara J, et al. Priming of protective $\mathrm{T}$ cell responses against virus-induced tumors in mice with human immune system components. J Exp Med. (2009) 206:1423-34. doi: 10.1084/ jem.20081720

17. Yajima M, Imadome K, Nakagawa A, Watanabe S, Terashima K, Nakamura $\mathrm{H}$, et al. A new humanized mouse model of Epstein-Barr virus infection that reproduces persistent infection, lymphoproliferative disorder, and cellmediated and humoral immune responses. J Infect Dis. (2008) 198:673-82. doi: 10.1086/590502

18. Ma SD, Hegde S, Young KH, Sullivan R, Rajesh D, Zhou Y, et al. A new model of Epstein-Barr virus infection reveals an important role for early lytic viral protein expression in the development of lymphomas. J Virol. (2011) 85:165-77. doi: 10.1128/jvi.01512-10

19. Chijioke O, Muller A, Feederle R, Barros MH, Krieg C, Emmel V, et al. Human natural killer cells prevent infectious mononucleosis features by targeting lytic Epstein-Barr virus infection. Cell Rep. (2013) 5:1489-98. doi: 10.1016/j.celrep. 2013.11.041

20. Murer A, McHugh D, Caduff N, Kalchschmidt JS, Barros MH, Zbinden $\mathrm{A}$, et al. EBV persistence without its EBNA3A and $3 \mathrm{C}$ oncogenes in vivo. PLoS Pathog. (2018) 14:e1007039. doi: 10.1371/journal.ppat.100 7039

21. Caduff N, McHugh D, Murer A, Ramer P, Raykova A, Landtwing V, et al. Immunosuppressive FK506 treatment leads to more frequent EBVassociated lymphoproliferative disease in humanized mice. PLoS Pathog. (2020) 16:e1008477. doi: 10.1371/journal.ppat.1008477
22. Kurth J, Spieker T, Wustrow J, Strickler GJ, Hansmann LM, Rajewsky K, et al. EBV-infected B cells in infectious mononucleosis: viral strategies for spreading in the B cell compartment and establishing latency. Immunity. (2000) 13:485-95. doi: 10.1016/s1074-7613(00)00048-0

23. McHugh D, Caduff N, Barros MHM, Rämer P, Raykova A, Murer A, et al. Persistent KSHV infection increases EBV-associated tumor formation in vivo via enhanced EBV lytic gene expression. Cell Host Microbe. (2017) 22:61-73. doi: 10.1016/j.chom.2017.06.009

24. Heuts F, Rottenberg ME, Salamon D, Rasul E, Adori M, Klein G, et al. $\mathrm{T}$ cells modulate Epstein-Barr virus latency phenotypes during infection of humanized mice. J Virol. (2014) 88:3235-45. doi: 10.1128/jvi.02885-13

25. McHugh D, Myburgh R, Caduff N, Spohn M, Kok YL, Keller CW, et al. EBV renders B cells susceptible to HIV-1 in humanized mice. Life Sci Alliance. (2020) 3:e202000640.

26. Babcock JG, Hochberg D, Thorley-Lawson AD. The expression pattern of Epstein-Barr virus latent genes in vivo is dependent upon the differentiation stage of the infected B cell. Immunity. (2000) 13:497-506. doi: 10.1016/s10747613(00)00049-2

27. Hochberg D, Middeldorp JM, Catalina M, Sullivan JL, Luzuriaga K, ThorleyLawson DA. Demonstration of the Burkitt's lymphoma Epstein-Barr virus phenotype in dividing latently infected memory cells in vivo. Proc Natl Acad Sci USA. (2004) 101:239-44. doi: 10.1073/pnas.2237267100

28. Babcock GJ, Decker LL, Volk M, Thorley-Lawson DA. EBV persistence in memory B cells in vivo. Immunity. (1998) 9:395-404. doi: 10.1016/s10747613(00)80622-6

29. Laichalk LL, Thorley-Lawson DA. Terminal differentiation into plasma cells initiates the replicative cycle of Epstein-Barr virus in vivo. J Virol. (2005) 79:1296-307. doi: 10.1128/jvi.79.2.1296-1307.2005

30. Antsiferova O, Müller A, Rämer P, Chijioke O, Chatterjee B, Raykova A, et al. Adoptive transfer of EBV specific $\mathrm{CD} 8^{+} \mathrm{T}$ cell clones can transiently control EBV infection in humanized mice. PLoS Pathog. (2014) 10:e1004333. doi: 10.1371/journal.ppat.1004333

31. Tsai MH, Raykova A, Klinke O, Bernhardt K, Gartner K, Leung CS, et al. Spontaneous lytic replication and epitheliotropism define an Epstein-Barr virus strain found in carcinomas. Cell Rep. (2013) 5:458-70. doi: 10.1016/j. celrep.2013.09.012

32. Tsai MH, Lin X, Shumilov A, Bernhardt K, Feederle R, Poirey R, et al. The biological properties of different Epstein-Barr virus strains explain their association with various types of cancers. Oncotarget. (2017) 8:10238-54. doi: 10.18632/oncotarget.14380

33. Chatterjee B, Deng Y, Holler A, Nunez N, Azzi T, Vanoaica LD, et al. $\mathrm{CD}^{+} \mathrm{T}$ cells retain protective functions despite sustained inhibitory receptor expression during Epstein-Barr virus infection in vivo. PLoS Pathog. (2019) 15:e1007748. doi: 10.1371/journal.ppat.1007748

34. White RE, Ramer PC, Naresh KN, Meixlsperger S, Pinaud L, Rooney C, et al. EBNA3B-deficient EBV promotes B cell lymphomagenesis in humanized mice and is found in human tumors. J Clin Invest. (2012) 122:1487-502.

35. Gottschalk S, Ng CY, Perez M, Smith CA, Sample C, Brenner MK, et al. An Epstein-Barr virus deletion mutant associated with fatal lymphoproliferative disease unresponsive to therapy with virus-specific CTLs. Blood. (2001) 97:835-43. doi: 10.1182/blood.v97.4.835

36. Cesarman E, Chang Y, Moore PS, Said JW, Knowles DM. Kaposi's sarcomaassociated herpesvirus-like DNA sequences in AIDS-related body-cavitybased lymphomas. N Engl J Med. (1995) 332:1186-91. doi: 10.1056/ nejm199505043321802

37. Carbone A, Cilia AM, Gloghini A, Capello D, Todesco M, Quattrone $\mathrm{S}$, et al. Establishment and characterization of EBV-positive and EBVnegative primary effusion lymphoma cell lines harbouring human herpesvirus type-8. Br J Haematol. (1998) 102:1081-9. doi: 10.1046/j.1365-2141.1998.0 0877.x

38. Wang LX, Kang G, Kumar P, Lu W, Li Y, Zhou Y, et al. Humanized-BLT mouse model of Kaposi's sarcoma-associated herpesvirus infection. Proc Natl Acad Sci USA. (2014) 111:3146-51. doi: 10.1073/pnas.1318175111

39. Bruce AG, Barcy S, Staheli J, Bielefeldt-Ohmann H, Ikoma M, Howard K, et al. Experimental co-transmission of simian immunodeficiency virus (SIV) and the macaque homologs of the Kaposi Sarcoma-associated herpesvirus (KSHV) and Epstein-Barr Virus (EBV). PLoS One. (2018) 13:e0205632. doi: 10.1371/journal.pone.0205632 
40. Labo N, Marshall V, Miley W, Davis E, McCann B, Stolka KB, et al. Mutual detection of Kaposi's sarcoma-associated herpesvirus and Epstein-Barr virus in blood and saliva of cameroonians with and without Kaposi's sarcoma. Int J Cancer. (2019) 145:2468-77. doi: 10.1002/ijc.32546

41. Faure A, Hayes M, Sugden B. How Kaposi's sarcoma-associated herpesvirus stably transforms peripheral B cells towards lymphomagenesis. Proc Natl Acad Sci USA. (2019) 116:16519-28. doi: 10.1073/pnas.1905025116

42. Klein U, Gloghini A, Gaidano G, Chadburn A, Cesarman E, Dalla-Favera $\mathrm{R}$, et al. Gene expression profile analysis of AIDS-related primary effusion lymphoma (PEL) suggests a plasmablastic derivation and identifies PELspecific transcripts. Blood. (2003) 101:4115-21. doi: 10.1182/blood-2002-103090

43. Luzuriaga K, Sullivan JL. Infectious mononucleosis. N Engl J Med. (2010) 362:1993-2000.

44. Landtwing V, Raykova A, Pezzino G, Beziat V, Marcenaro E, Graf C, et al. Cognate HLA absence in trans diminishes human NK cell education. J Clin Invest. (2016) 126:3772-82. doi: 10.1172/jci86923

45. Azzi T, Lunemann A, Murer A, Ueda S, Beziat V, Malmberg KJ, et al. Role for early-differentiated natural killer cells in infectious mononucleosis. Blood. (2014) 124:2533-43. doi: 10.1182/blood-2014-01-553024

46. Hendricks DW, Balfour HH Jr., Dunmire SK, Schmeling DO, Hogquist KA, Lanier LL. Cutting edge: $\mathrm{NKG} 2 \mathrm{C}^{h i} \mathrm{CD} 57^{+} \mathrm{NK}$ cells respond specifically to acute infection with cytomegalovirus and not Epstein-Barr virus. J Immunol. (2014) 192:4492-6. doi: 10.4049/jimmunol.1303211

47. Williams H, McAulay K, Macsween KF, Gallacher NJ, Higgins CD, Harrison $\mathrm{N}$, et al. The immune response to primary EBV infection: a role for natural killer cells. Br J Haematol. (2005) 129:266-74. doi: 10.1111/j.1365-2141.2005. 05452.x

48. Balfour HH Jr., Odumade OA, Schmeling DO, Mullan BD, Ed JA, Knight JA, et al. Behavioral, virologic, and immunologic factors associated with acquisition and severity of primary Epstein-Barr virus infection in university students. J Infect Dis. (2013) 207:80-8. doi: 10.1093/infdis/jis646

49. Pappworth IY, Wang EC, Rowe M. The switch from latent to productive infection in Epstein-Barr virus-infected B cells is associated with sensitization to NK cell killing. J Virol. (2007) 81:474-82. doi: 10.1128/jvi.01777-06

50. Xiang Z, Liu Y, Zheng J, Liu M, Lv A, Gao Y, et al. Targeted activation of human Vgamma9Vdelta2-T cells controls Epstein-Barr virus-induced B cell lymphoproliferative disease. Cancer Cell. (2014) 26:565-76. doi: 10.1016/j.ccr. 2014.07.026

51. Zumwalde NA, Sharma A, Xu X, Ma S, Schneider CL, Romero-Masters JC, et al. Adoptively transferred Vgamma9Vdelta2 $\mathrm{T}$ cells show potent antitumor effects in a preclinical B cell lymphomagenesis model. JCI Insight. (2017) 2:e93179.

52. Djaoud Z, Guethlein LA, Horowitz A, Azzi T, Nemat-Gorgani N, Olive D, et al. Two alternate strategies for innate immunity to Epstein-Barr virus: one using NK cells and the other NK cells and gammadelta T cells. J Exp Med. (2017) 214:1827-41. doi: 10.1084/jem.20161017

53. Djaoud Z, Parham P. Dimorphism in the TCRgamma-chain repertoire defines 2 types of human immunity to Epstein-Barr virus. Blood Adv. (2020) 4:1198205. doi: 10.1182/bloodadvances.2019001179

54. Yuling H, Ruijing X, Li L, Xiang J, Rui Z, Yujuan W, et al. EBV-induced human $\mathrm{CD}^{+}$NKT cells suppress tumorigenesis by EBV-associated malignancies. Cancer Res. (2009) 69:7935-44. doi: 10.1158/0008-5472.can-09-0828

55. Chung BK, Tsai K, Allan LL, Zheng DJ, Nie JC, Biggs CM, et al. Innate immune control of EBV-infected B cells by invariant natural killer T cells. Blood. (2013) 122:2600-8. doi: 10.1182/blood-2013-01-480665

56. Pasquier B, Yin L, Fondaneche MC, Relouzat F, Bloch-Queyrat C, Lambert N, et al. Defective NKT cell development in mice and humans lacking the adapter SAP, the X-linked lymphoproliferative syndrome gene product. J Exp Med. (2005) 201:695-701. doi: 10.1084/jem.20042432

57. Heslop HE, Brenner MK, Rooney CM. Donor $\mathrm{T}$ cells to treat EBVassociated lymphoma. N Engl J Med. (1994) 331:679-80. doi: 10.1056/ nejm199409083311017

58. Icheva V, Kayser S, Wolff D, Tuve S, Kyzirakos C, Bethge W, et al. Adoptive transfer of epstein-barr virus (EBV) nuclear antigen 1-specific $\mathrm{T}$ cells as treatment for EBV reactivation and lymphoproliferative disorders after allogeneic stem-cell transplantation. J Clin Oncol. (2013) 31:39-48. doi: 10.1200/jco.2011.39.8495
59. Bollard CM, Gottschalk S, Torrano V, Diouf O, Ku S, Hazrat Y, et al. Sustained complete responses in patients with lymphoma receiving autologous cytotoxic T lymphocytes targeting Epstein-Barr virus latent membrane proteins. J Clin Oncol. (2014) 32:798-808. doi: 10.1200/jco.2013.51.5304

60. Yajima M, Imadome K, Nakagawa A, Watanabe S, Terashima K, Nakamura $\mathrm{H}$, et al. T cell-mediated control of Epstein-Barr virus infection in humanized mice. J Infect Dis. (2009) 200:1611-5. doi: 10.1086/644644

61. Linnerbauer S, Behrends U, Adhikary D, Witter K, Bornkamm GW, Mautner J. Virus and autoantigen-specific $\mathrm{CD} 4^{+} \mathrm{T}$ cells are key effectors in a SCID mouse model of EBV-associated post-transplant lymphoproliferative disorders. PLoS Pathog. (2014) 10:e1004068. doi: 10.1371/journal.ppat.1004068

62. Chijioke O, Marcenaro E, Moretta A, Capaul R, Münz C. The SAP-dependent 2B4 receptor mediates $\mathrm{CD}^{+} \mathrm{T}$ cell dependent immune control of Epstein Barr virus infection in mice with reconstituted human immune system components. J Infect Dis. (2015) 212:803-7. doi: 10.1093/infdis/jiv114

63. Danisch S, Slabik C, Cornelius A, Albanese M, Tagawa T, Chen YA, et al. Spatiotemporally skewed activation of programmed cell death receptor 1positive $\mathrm{T}$ cells after Epstein-Barr virus infection and tumor development in long-term fully humanized mice. Am J Pathol. (2019) 189:521-39. doi: 10.1016/j.ajpath.2018.11.014

64. Leong YA, Chen Y, Ong HS, Wu D, Man K, Deleage C, et al. CXCR5 ${ }^{+}$follicular cytotoxic T cells control viral infection in B cell follicles. Nat Immunol. (2016) 17:1187-96.

65. Johnson DB, McDonnell WJ, Gonzalez-Ericsson PI, Al-Rohil RN, Mobley BC, Salem JE, et al. A case report of clonal EBV-like memory CD4 ${ }^{+} \mathrm{T}$ cell activation in fatal checkpoint inhibitor-induced encephalitis. Nat Med. (2019) 25:1243-50. doi: 10.1038/s41591-019-0523-2

66. Ma SD, Xu X, Jones R, Delecluse HJ, Zumwalde NA, Sharma A, et al. PD1/CTLA-4 blockade inhibits Epstein-Barr virus-induced lymphoma growth in a cord blood humanized-mouse model. PLoS Pathog. (2016) 12:e1005642. doi: 10.1371/journal.ppat.1005642

67. Murer A, Ruhl J, Zbinden A, Capaul R, Hammerschmidt W, Chijioke O, et al. MicroRNAs of Epstein-Barr virus attenuate T-cell-mediated immune control in vivo. MBio. (2019) 10:e01941-18.

68. Ma SD, Xu X, Plowshay J, Ranheim EA, Burlingham WJ, Jensen JL, et al. LMP1-deficient Epstein-Barr virus mutant requires $\mathrm{T}$ cells for lymphomagenesis. J Clin Invest. (2015) 125:304-15. doi: 10.1172/jci76357

69. Rühl J, Leung CS, Münz C. Vaccination against the Epstein-Barr virus. Cell Mol Life Sci. (2020) 1-10. doi: 10.1007/s00018-020-03538-3

70. Taylor GS, Haigh TA, Gudgeon NH, Phelps RJ, Lee SP, Steven NM, et al. Dual stimulation of Epstein-Barr Virus (EBV)-specific CD4 ${ }^{+}$- and $\mathrm{CD} 8^{+}-\mathrm{T}$ cell responses by a chimeric antigen construct: potential therapeutic vaccine for EBV-positive nasopharyngeal carcinoma. J Virol. (2004) 78:768-78. doi: 10.1128/jvi.78.2.768-778.2004

71. Taylor GS, Jia H, Harrington K, Lee LW, Turner J, Ladell K, et al. A recombinant modified vaccinia Ankara vaccine encoding Epstein-Barr virus (EBV) target antigens: a phase I trial in UK patients with EBV-positive cancer. Clin Cancer Res. (2014) 20:5009-22. doi: 10.1158/1078-0432.ccr-14-1122-t

72. Hui EP, Taylor GS, Jia H, Ma BB, Chan SL, Ho R, et al. Phase I trial of recombinant modified vaccinia Ankara encoding Epstein-Barr viral tumor antigens in nasopharyngeal carcinoma patients. Cancer Res. (2013) 73:167688. doi: 10.1158/0008-5472.can-12-2448

73. Smith C, Tsang J, Beagley L, Chua D, Lee V, Li V, et al. Effective treatment of metastatic forms of Epstein-Barr virus-associated nasopharyngeal carcinoma with a novel adenovirus-based adoptive immunotherapy. Cancer Res. (2012) 72:1116-25. doi: 10.1158/0008-5472.can-11-3399

74. Rühl J, Citterio C, Engelmann C, Haigh TA, Dzionek A, Dreyer JH, et al. Heterologous prime-boost vaccination protects from EBV antigen expressing lymphomas. J Clin Invest. (2019) 129:2071-87. doi: 10.1172/jci125364

75. Gurer C, Strowig T, Brilot F, Pack M, Trumpfheller C, Arrey F, et al. Targeting the nuclear antigen 1 of Epstein Barr virus to the human endocytic receptor DEC-205 stimulates protective T-cell responses. Blood. (2008) 112:1231-9. doi: 10.1182/blood-2008-03-148072

76. Meixlsperger S, Leung CS, Ramer PC, Pack M, Vanoaica LD, Breton $\mathrm{G}$, et al. $\mathrm{CD}_{141}{ }^{+}$dendritic cells produce prominent amounts of IFNalpha after dsRNA recognition and can be targeted via DEC-205 in humanized mice. Blood. (2013) 121:5034-44. doi: 10.1182/blood-2012-12-47 3413 
77. van Zyl DG, Tsai MH, Shumilov A, Schneidt V, Poirey R, Schlehe B, et al. Immunogenic particles with a broad antigenic spectrum stimulate cytolytic $\mathrm{T}$ cells and offer increased protection against EBV infection ex vivo and in mice. PLoS Pathog. (2018) 14:e1007464. doi: 10.1371/journal.ppat.1007464

78. Douam F, Ziegler CGK, Hrebikova G, Fant B, Leach R, Parsons L, et al. Selective expansion of myeloid and NK cells in humanized mice yields humanlike vaccine responses. Nat Commun. (2018) 9:5031.

79. Li Y, Masse-Ranson G, Garcia Z, Bruel T, Kok A, Strick-Marchand H, et al. A human immune system mouse model with robust lymph node development. Nat Methods. (2018) 15:623-30. doi: 10.1038/s41592-018-0071-6

80. Salguero G, Daenthanasanmak A, Münz C, Raykova A, Guzman CA, Riese P, et al. Dendritic cell-mediated immune humanization of mice: implications for allogeneic and xenogeneic stem cell transplantation. J Immunol. (2014) 192:4636-47. doi: 10.4049/jimmunol.1302887
81. Grant ML, Bollard CM. Cell therapies for hematological malignancies: don't forget non-gene-modified t cells! Blood Rev. (2018) 32:203-24. doi: 10.1016/j. blre.2017.11.004

Conflict of Interest: The author declares that the research was conducted in the absence of any commercial or financial relationships that could be construed as a potential conflict of interest.

Copyright $\odot 2020$ Münz. This is an open-access article distributed under the terms of the Creative Commons Attribution License (CC BY). The use, distribution or reproduction in other forums is permitted, provided the original author(s) and the copyright owner(s) are credited and that the original publication in this journal is cited, in accordance with accepted academic practice. No use, distribution or reproduction is permitted which does not comply with these terms. 